\title{
DYNAMICS OF SYSTEMIC INFLAMIMATORY RESPONSE MARKERS IN PATIENTS WITH URGENT CONDITIONS DEPEND-ING ON THE DEVELOPMIENT OF SEPSIS
}

\section{G.V. Bulava, A.K. Shabanov*, O.V. Nikitina, E.V. Kislukhina}

General Resuscitation Department, N.V. Sklifosovsky Research Institute for Emergency Medicine of the Moscow Healthcare Department, Moscow, Russian Federation

*Contacts: Aslan K. Shabanov, Senior Researcher, General Resuscitation Department, N.V. Sklifosovsky Research Institute for Emergency Medicine. E-mail: aslan_s@mail.ru

BACKGROUND There is still no information on the dynamics of pro- and anti-inflammatory cytokines and mark-ers of the septic process before the clinical manifestation of sepsis.

THE AIM OF THE STUDY was to analyze the dynamics of inflammation and sepsis markers concentration in early periods in patients with urgent pathology, depending on the subsequently developed sepsis.

MATERIALS AND METHODS. The concentration of procalcitonin, C-reactive protein, LBP, IL-6, IL-10, IL-2R in 61 patients with a high risk of sepsis was investigated starting from the first day after admission to the hospital and then with intervals of $3-5$ days. The Group 1 included 29 patients with verified sepsis. All patients of this group survived. The Group 2 included 8 patients who died. The Group 3 included 24 patients who had no clinical signs of sepsis. All the patients in this group recovered.

RESULTS. We revealed significant differences in concentrations of systemic inflammatory response markers and its dynamics in the period preceding clinical manifestations of sepsis. It was found that it was possible to predict the development of sepsis and its unfavorable outcome with a high statistical probability in the study of paired samples of blood serum of patients received on day 1-3 and 4-6 from the onset of the disease or severe trauma. The predictors were multidirectional changes of IL-6, IL-10, LBP concentrations and more than three-fold IL-2R increase on the background of high concentrations of procalcitonin and C-reactive protein.

CONCLUSION. The highest concentrations of procalcitonin, C-reactive protein, IL-10 and IL-2R were revealed within the first three days in patients who died of sepsis. High concentrations of IL- 6 and IL-10 within first three days and different directions of their concentrations during the next $4-6$ days indicate the development of sepsis with an unfavorable outcome. Reduction of IL-2R and IL-6 and an increase in IL-10 within the first week after the onset of the disease or trau-ma are predictors of lethal outcome.

Key words: urgent conditions, systemic inflammatory response, early predictors of sepsis and lethal outcome

For citation Bulava G.V., Shabanov A.K., Nikitina O.V., Kislukhina E.V. Dynamics of systemic inflammatory response markers in patients with urgent conditions depend-ing on the development of sepsis. Russian Sklifosovsky Journal of Emergency Medical Care. 2018; 7(1): 13-19. DOI: 10.23934/2223-90222018-7-1-13-19 (In Russian)

Conflict of interest Authors declare lack of the conflicts of interests

Acknowledgments The study had no sponsorship

CRP - C-reactive protein

IL - interleukin

IL-2R - interleukin-2

LPSBP - lipopolysaccharide-binding peptide

PCT - procalcitonin

TNF-alpha - tumor necrosis factor alpha

\section{INTRODUCTION}

Despite numerous studies devoted to determining the diagnostic and prognostic significance of biomarkers associated with the development of sepsis, there is still no consensus on interpreting their results. The main difficulty is tha concentrations of many marker molecules significantly increase not only with the development of sepsis, but also in the first 2 days from the onset of acute inflammatory disease or immediately after a mechanical trauma, burn injury or extensive surgical intervention even in patients who did not have septic complications in later terms. The increase in reference values of procalcitonin (PCT), C-reactive protein (CRP), interleukin-6 (IL-6) and interleukin-10 (IL-10), lipopolysaccharide-binding peptide (LPSBP) and soluble interleukin-2 receptor (IL-2R) in the early period is described in a number of works. Moreover, a favorable course of the disease is accompanied by a fall in their level to normal values within 2-3 days, and a multiple increase in later periods is noted only in case of infection and the development of sepsis [1-4].

As a rule, the concentration of mediators in the peripheral blood varies with the activity of the inflammatory process, but an excessively high level of cytokines can promote the development of severe multi-organ dysfunction and sepsis. According to the authors, the determination of the level of some cytokines, for example, interleukins, can be used to predict multi-organ failure in patients with multiple trauma [5].

The results of our studies also showed an increase in the concentration of some biomarkers in the blood of patients with surgical diseases and severe multisystem trauma already on day 1-2. In patients with developed sepsis, concentrations of LPSBP, CRP, IL-2R and IL-6 in blood were significantly higher and differed with high statistical significance from levels in patients who hadn't had septic complications [6].

Features of the dynamics of some pro- and anti-inflammatory cytokines in the course of developed sepsis are described in a number of scientific articles. The variants of concentration of IL-6, IL-10, tumor necrosis factor alpha (TNF-alpha,) PCT, reflecting the type of the response in the course of the developed septic process and directly associated with its outcomes were determined [7, 8]. However, there is no information on the dynamics of pro- and anti-inflammatory cytokines, as well as markers of the septic process before the clinical manifestation of sepsis. 
The purpose of this article was to study the dynamics of concentrations of inflammatory and septic markers in early periods in patients with urgent confition, depending on the subsequently developed sepsis.

\section{MATERIAL AND METHODS}

Starting with the first day after the onset of the disease, multisystem trauma or surgical intervention, and further with an interval of 3-5 days, the concentration of PCT, CRP, LPSBP, IL-6, IL-10 and IL-2R in patients with a high risk of sepsis was investigated. We studied blood samples of 61 patients who were treated at the Institute for severe multisystem injury with damage to three or more anatomical areas (ISS $>25$ ), destructive pancreatitis, purulent mediastinitis and diffuse purulent peritonitis.

Depending on the development of sepsis and its outcomes, patients were divided into three groups. The $1^{\text {st }}$ group included 29 patients with verified sepsis, which complicated mediastinitis in 6 patients, common purulent peritonitis in 8 patients, severe destructive pancreatitis in 3 patients, and severe multisystem injury in 12 patients (ISS $\geqslant 25$ ). In 4 patients of the 1 st group, a septic shock developed. All patients of this group survived.

Deaths from sepsis and septic shock patients occurred the $2^{\text {nd }}$ group, which included 8 patients: 2 patients with mediastinitis, 4 cases of pancreatonecrosis and 2 cases of severe multisystem trauma.

The $3^{\text {rd }}$ group included 24 patients who did not have a clinical picture of sepsis: 2 - mediastinitis, $2-$ peritonitis, 2 - acute destructive pancreatitis and 18 - severe multisystem trauma (ISS $\geqslant 25)$. All the patients in this group recovered.

The age group and the gender composition of the group are comparable: there were 7 women and 22 men in the first group, 2 women and 6 men in the second group, and 7 women and 17 men in the third group. The mean age of the patients was $45.9 \pm 8.5,49.9 \pm 6.7$ and $44.0 \pm 4.1$ years, respectively.

All patients who needed urgent surgical treatment were operated. In the conditions of resuscitation departments all patients received complex treatment, including infusion, transfusion, antibacterial and detoxification therapy.

The concentration of PCT, IL- 6 and IL-10 was determined by an enzyme immunoassay using a set of Vector-Best reagents on a microtiter plate of Synergy NT (Bio-Tek Instruments, USA). CRP was examined on an automatic analyzer BN "ProSpec" (Dade Behring, Germany). LBP and IL-2R were determined on an IMMULITE 2000 automatic immunochemiluminescent analyzer (DPC, USA).

Statistical processing of the data was carried out using application packages MS Excel, STATISTICA and SPSS. Estimates of central trends and their variations are represented by mean values $(\mathrm{M})$ and standard deviations $(\sigma)$, as well as medians (Me) with a quarter scale (1st and 3rd quartiles), because half of the distributions did not meet the criterion of normality. The comparison of quantitative data in the groups was carried out using the nonparametric Mann-Whitney test. The level of statistical significance was $p \leqslant 0.05$.

\section{RESULTS AND DESCUSSION}

The analysis of studied parameters and their dynamics during the observation period revealed differences both in concentration and direction of changes in patients of the compared groups (Fig. 1). Despite the fact that the levels of biomarkers in the compared groups were determined in a wide range of values, in the patients with sepsis the average concentrations and medians of CRP, LPSBP, IL-2R during the first week of observation were significantly higher than the values corresponding to the upper limits of the norms, and higher than in patients without sepsis (Table 1). In the group of deceased patients, concentrations of PCT, CRP, LPSBP and IL-2R also statistically significantly exceeded the levels in patients of the $1^{\text {st }}$ and $3^{\text {rd }}$ group (Table 2).

PCT
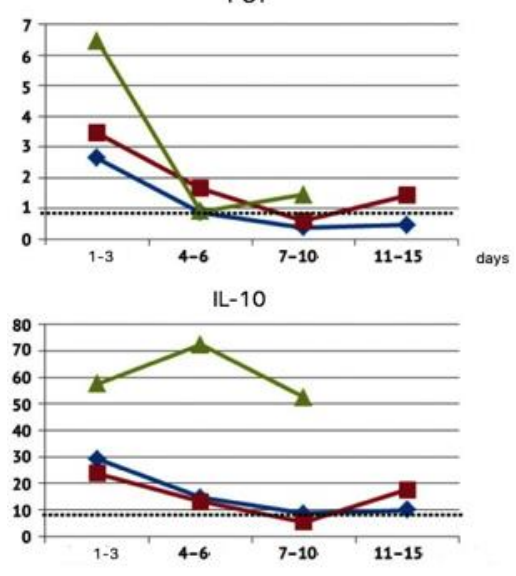

CRP
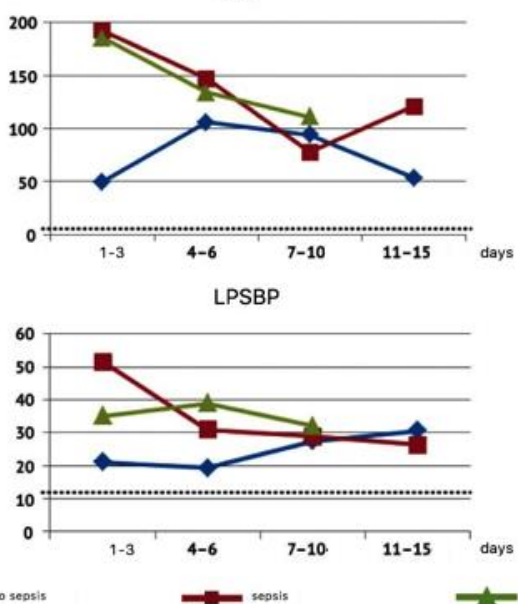

IL-6
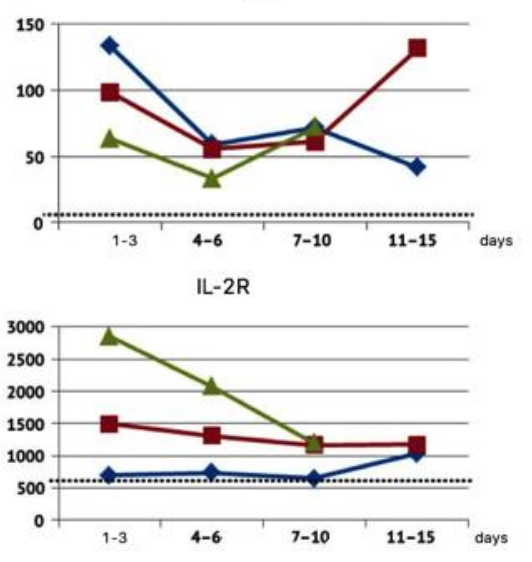

Fig. 1. The dynamics of inflammation markers, in relation to the development of sepsis and its outcome. Dotted lines are the upper limits of the norm (according to medians).

Notes: CRP - C-reactive protein; IL - interleukin; IL-2R - interleukin 2R; LPSBP - lipopolysaccharide-binding peptide; PC - procalcitonin 
Table 1

The dynamics of systemic inflammatory response markers in relation to the development of sepsis

\begin{tabular}{|c|c|c|c|c|c|c|c|}
\hline \multirow[t]{2}{*}{ Day } & \multirow[t]{2}{*}{ Groups } & \multicolumn{6}{|c|}{ Studied parameters ( $M \pm \sigma ;$ Med [1, 3 quartiles]) } \\
\hline & & РCT & $C R P$ & IL-6 & IL-10 & IL-2R & LPSBP \\
\hline \multirow[t]{3}{*}{$1-3$} & 1 (sepsis) & $\begin{array}{c}6.61 \pm 9.18 \\
3.45[1.78 ; 7.32]\end{array}$ & $\begin{array}{c}195.15 \pm 91.03 \\
192.5[97.1 ; 251]\end{array}$ & $\begin{array}{l}472.94 \pm 1,026.66 \\
98.4[54.2 ; 391]\end{array}$ & $\begin{array}{c}41.36 \pm 46.26 \\
23.82[12.62 ; 46.8]\end{array}$ & $\begin{array}{c}2,100.8 \pm 1,711.32 \\
1,491.5[1,104 ; 2,415]\end{array}$ & $\begin{array}{c}56.91 \pm 30.37 \\
51.6[36,65 ; 80,75]\end{array}$ \\
\hline & 2 (died of sepsis) & $\begin{array}{c}23.76 \pm 37.72 \\
6.46[5.75 ; 14]\end{array}$ & $\begin{array}{c}201.48 \pm 62,31 \\
185.5[167 ; 272]\end{array}$ & $\begin{array}{c}89.35 \pm 69.06 \\
63.23[44.15 ; 108.73]\end{array}$ & $\begin{array}{c}123.22 \pm 136.74 \\
57.61[32.69 ; 161]\end{array}$ & $\begin{array}{c}3,316.6 \pm 1,955.52 \\
2,847[2,374 ; 4,171]\end{array}$ & $\begin{array}{c}44.03 \pm 17.76 \\
35.05[32.1 ; 60.3]\end{array}$ \\
\hline & 3 (without sepsis) & $\begin{array}{c}5.53 \pm 7.96 \\
2.64[1.08 ; 5.55]\end{array}$ & $\begin{array}{c}57.33 \pm 54.06 \\
49.6[23.5 ; 92.5]\end{array}$ & $\begin{array}{c}212.42 \pm 352.54 \\
133.6[57.15 ; 174.3]\end{array}$ & $\begin{array}{c}54.8 \pm 48.64 \\
29.11[17.72 ; 92.56]\end{array}$ & $\begin{array}{c}830.77 \pm 511.42 \\
690[549 ; 1,057]\end{array}$ & $\begin{array}{c}19.51 \pm 9.98 \\
21[15.7 ; 28.2]\end{array}$ \\
\hline \multirow[t]{3}{*}{$4-6$} & 1 (sepsis) & $\begin{array}{c}2.13 \pm 1.82 \\
1.65[0.58 ; 2.94]\end{array}$ & $\begin{array}{c}162.78 \pm 58.72 \\
147[135 ; 167]\end{array}$ & $\begin{array}{c}76.94 \pm 82.78 \\
55.6[27.3 ; 76.7]\end{array}$ & $\begin{array}{c}20.12 \pm 21.8213 .01 \\
{[6.43 ; 20.82]}\end{array}$ & $\begin{array}{c}1,594.19 \pm 966.88 \\
1,308[931 ; 1,825.5]\end{array}$ & $\begin{array}{c}37.89 \pm 20.6930 .9 \\
{[24.1 ; 44.3]}\end{array}$ \\
\hline & 2 (died of sepsis) & $\begin{array}{c}2.02 \pm 1.9 \\
0.91[0.84 ; 3.41]\end{array}$ & $\begin{array}{c}144.98 \pm 88.01 \\
134[69.75 ; 208.5]\end{array}$ & $\begin{array}{c}58.6 \pm 75.81 \\
33.15[15.92 ; 61.85]\end{array}$ & $\begin{array}{c}124.43 \pm 148.04 \\
72.4[7.16 ; 234.49]\end{array}$ & $\begin{array}{c}2,392.82 \pm 2,110.97 \\
2,073[1,294 ; 2,636.5]\end{array}$ & $\begin{array}{c}39.98 \pm 23.03 \\
38.95[21.35 ; 58.1]\end{array}$ \\
\hline & 3 (without sepsis) & $\begin{array}{c}1.99 \pm 2.55 \\
0.87[0.45 ; 1.96]\end{array}$ & $\begin{array}{c}95.6 \pm 48.5 \\
106[90.7 ; 121]\end{array}$ & $\begin{array}{c}76.67 \pm 71.97 \\
59.1[18.25 ; 126.9]\end{array}$ & $\begin{array}{c}18.36 \pm 18.09 \\
14.64[5.67 ; 20.03]\end{array}$ & $\begin{array}{c}1,061,88 \pm 1,076.79 \\
736[463 ; 1,026]\end{array}$ & $\begin{array}{c}23.13 \pm 14.25 \\
19.25[10.75 ; 37.35]\end{array}$ \\
\hline \multirow[t]{3}{*}{$7-10$} & 1 (sepsis) & $\begin{array}{c}1.65 \pm 2.36 \\
0.58[0.31 ; 3.45]\end{array}$ & $\begin{array}{c}90.44 \pm 70.1377 .5 \\
{[57.5 ; 89.4]}\end{array}$ & $\begin{array}{c}75.12 \pm 94.28 \\
60.85[26 ; 79.4]\end{array}$ & $\begin{array}{c}9.41 \pm 7.63 \\
5.36[4.17 ; 13.43]\end{array}$ & $\begin{array}{c}1,161 \pm 460,76 \\
1,161[902 ; 1,670]\end{array}$ & $\begin{array}{c}29.33 \pm 15.84 \\
28.85[18 ; 36.8]\end{array}$ \\
\hline & 2 (died of sepsis) & $\begin{array}{c}4.83 \pm 8.86 \\
1.44[0.82 ; 2.22]\end{array}$ & $\begin{array}{l}129.51 \pm 102.37 \\
111[65.6 ; 134]\end{array}$ & $\begin{array}{c}98.34 \pm 101.19 \\
71.6[25.85 ; 108.73]\end{array}$ & $\begin{array}{c}111.73 \pm 212.37 \\
52.5[14.19 ; 77.34]\end{array}$ & $\begin{array}{c}2,457.56 \pm 2,071.75 \\
1,200[1,094 ; 3,487]\end{array}$ & $\begin{array}{c}31.39 \pm 17.64 \\
32.1[19.9 ; 38.8]\end{array}$ \\
\hline & 3 (without sepsis) & $\begin{array}{c}0.56 \pm 0.53 \\
0.37[0.28 ; 0.62]\end{array}$ & $\begin{array}{c}101.23 \pm 50.91 \\
94.3[63.4 ; 123]\end{array}$ & $\begin{array}{c}72.37 \pm 88.87 \\
38.4[15.7 ; 81.4]\end{array}$ & $\begin{array}{c}37.35 \pm 96.97 \\
8.6[6.5 ; 15.44]\end{array}$ & $\begin{array}{l}793.11 \pm 425.92 \\
642[490 ; 935]\end{array}$ & $\begin{array}{c}31.53 \pm 10.2 \\
27.4[25.7 ; 40.4]\end{array}$ \\
\hline \multirow[t]{2}{*}{$11-15$} & 1 (sepsis) & $\begin{array}{c}6.27 \pm 7.72 \\
1.43[0.33 ; 14.5]\end{array}$ & $\begin{array}{c}106.37 \pm 52.5 \\
121[48.1 ; 150]\end{array}$ & $\begin{array}{c}150.58 \pm 107.98 \\
131.5[80.35 ; 220.8]\end{array}$ & $\begin{array}{c}43.95 \pm 57.38 \\
17.57[7.27 ; 47.05]\end{array}$ & $\begin{array}{c}1,173.5 \pm 740.34 \\
1,173.5[650 ; 1,697]\end{array}$ & $\begin{array}{c}26.25 \pm 8.56 \\
26.25[20.2 ; 32.3]\end{array}$ \\
\hline & 3 (without sepsis) & $\begin{array}{c}0.7 \pm 0.63 \\
0.45[0.26 ; 1.04]\end{array}$ & $\begin{array}{c}73.27 \pm 61.89 \\
53.3[17.3 ; 112]\end{array}$ & $\begin{array}{c}62.65 \pm 62.46 \\
41.25[14.7 ; 117]\end{array}$ & $\begin{array}{c}10.28 \pm 5.15 \\
9.93[5 ; 14.4]\end{array}$ & $\begin{array}{c}1,141.11 \pm 579.87 \\
1,027[772 ; 1,441]\end{array}$ & $\begin{array}{c}27.57 \pm 14.79 \\
30.6[16.2 ; 33.7]\end{array}$ \\
\hline
\end{tabular}

Notes: CRP - C-reactive protein; IL - interleukin; IL-2R - interleukin 2R; LPSBP - lipopolysaccharide-binding peptide; PC - procalcitonin

Table 2

P-values of the Mann-Whitney test for the parameters studied in the compared groups in dynamics

\begin{tabular}{|c|c|c|c|c|}
\hline \multirow[t]{2}{*}{ Parameters } & \multicolumn{4}{|c|}{ Terms of study (days from the onset of the disease or trauma) } \\
\hline & $1-3$ & $4-6$ & $7-10$ & $11-15$ \\
\hline \multicolumn{5}{|c|}{ Group 1 and 2} \\
\hline РCT & 0.07 & 1 & 0.29 & \\
\hline CRP & 0.82 & 0.34 & 0.29 & \\
\hline IL-6 & 0.1 & 0.31 & 0.47 & \\
\hline IL-10 & 0.08 & 0.1 & 0.06 & \\
\hline LPSBP & 0.37 & 0.71 & 0.78 & \\
\hline IL-2R & 0.09 & 0.21 & 0.27 & \\
\hline \multicolumn{5}{|c|}{ Group 1 and 3} \\
\hline PCT & 0.52 & 0.45 & 0.22 & 0.42 \\
\hline$C R P$ & 0.00005 & 0.02 & 0.43 & 0.36 \\
\hline IL-6 & 0.64 & 0.96 & 0.69 & 0.14 \\
\hline IL-10 & 0.29 & 0.91 & 0.32 & 0.16 \\
\hline
\end{tabular}




\begin{tabular}{|l|c|c|c|c|}
\hline LPSBP & $\mathbf{0 . 0 0 0 3}$ & 0.05 & 0.54 & 0.91 \\
\hline IL-2R & 0.001 & 0.03 & 0.11 & 0.91 \\
\hline \multicolumn{4}{|c|}{ Group 2 and 3 } \\
\hline PCT & $\mathbf{0 . 0 2}$ & 0.46 & $\mathbf{0 . 0 4}$ & \\
\hline CRP & $\mathbf{0 . 0 0 0 4}$ & 0.42 & 0.72 & \\
\hline IL-6 & 0.12 & 0.52 & 0.32 & \\
\hline IL-10 & 0.19 & 0.11 & 0.12 & \\
\hline LPSBP & $\mathbf{0 . 0 0 0 6}$ & 0.15 & 0.86 & \\
\hline IL-2R & $\mathbf{0 . 0 0 0 3}$ & 0.08 & 0.01 & \\
\hline
\end{tabular}

Notes: CRP - C-reactive protein; IL - interleukin; IL-2R - interleukin 2R; LPSBP - lipopolysaccharide-binding peptide; PC - procalcitonin

Attention is drawn to differences in both concentrations of detectable marker molecules in patients of the compared groups in the early periods, and the direction of their changes during the observation period.

The increase in the level of a number of cytokines and markers of sepsis in blood within first 2 days after trauma, surgery or the onset of acute surgical disease is noted in scientific publications and reflects activation of immunological mechanisms which provoke the inflammatory response and individual characteristics of each patient's immune response to damaging and stimulating effects, accompanied by the development of inflammation. The systemic reaction of the body to damage, regardless of the cause (acute blood loss, ischemia, reperfusion, fractures, mechanical, thermal or chemical trauma) reflects an attempt to restore homeostasis and includes coordination of the immune, cardiovascular, endocrine and nervous systems. Often the systemic response is accompanied by serious immunological disorders that threaten the survival of such patients. Concentrations of blood mediators change, as a rule, parallel to the activity of the inflammatory process and their excessively high level, as well as a violation of the balance of pro- and anti-inflammatory cytokines, can trigger the development of severe organ dysfunction and sepsis [5, 9].

The findings show that in patients of the 1st group with developed sepsis, clinically manifested after 7 days from the onset of the disease, there was a significant imbalance of IL-6, providing pro-inflammatory responses, and IL-10, which has an anti-inflammatory potential (Fig. 2). Excessive production of IL-6 during the whole period of observation and a slight increase in the concentration in the blood of IL-10 for 1-6 days created prerequisites for the development of sepsis. The same was facilitated by a decrease in the concentration of LPSBP (Fig. 3).

Deceased of sepsis

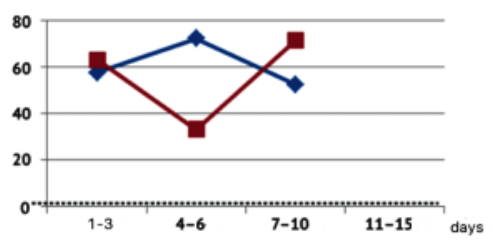

Survived (atter sepsis)

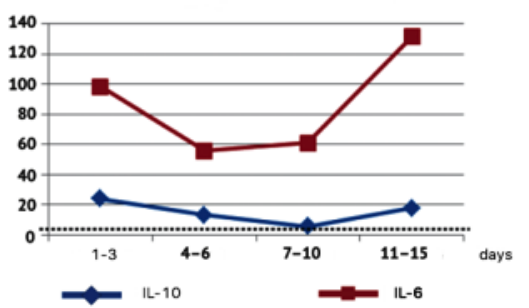

Survived (without sepsis)

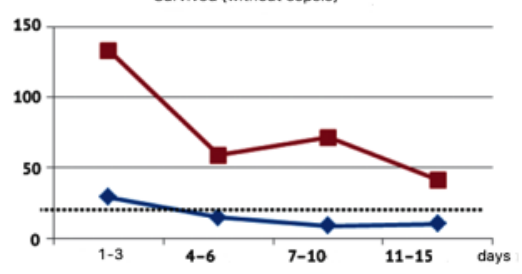

Fig. 2. The dynamics of proinflammatory IL- 6 and anti-inflammatory IL-10 cytokines, in relation to the development of sepsis and its outcomes (according to medians).

Notes: IL - interleukin Deceased of sepsis

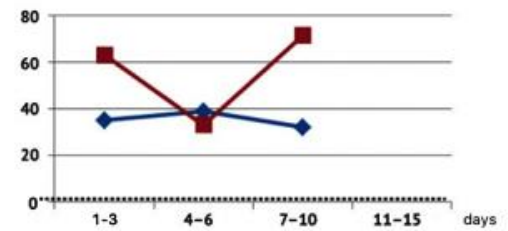

Survivors (atter sepsis)

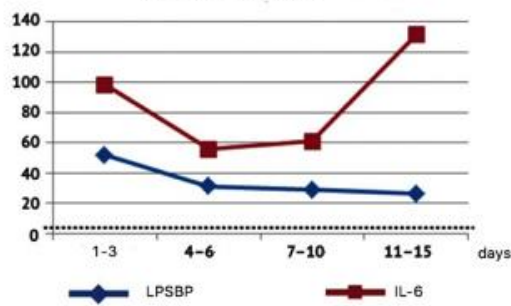

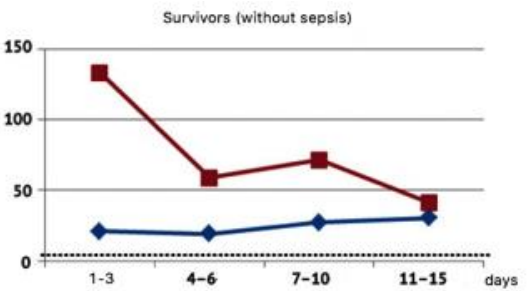

Fig. 3. The dynamics of IL-6 and lipopolysaccharide-binding protein, depending on the development of sepsis and its outcomes (according to medians). Dotted lines are the upper limits of normal values

Notes: IL - interleukin; LPSBP - lipopolysaccharide-binding peptide 
In patients of the $2^{\text {nd }}$ group who died from septicemia by day 4-6, the dynamics of these interleukins had a multidirectional character with hyperproduction of IL-10 and a sharp decrease in IL- 6 production. Such changes reflect the suppression of the inflammatory response which is required at these times to provide an adequate antiinfective response. In later periods, a sharp increase in the concentration of IL- 6 and IL-10 reduction created the prerequisites for the development of an uncontrolled systemic inflammatory response and sepsis that led to the death of patients (Fig. 2). IL-6 is the main pro-inflammatory cytokine, and a significant increase in its concentration is a sign of multi-organ failure and death [10]. Such multidirectional changes such as an increase in the concentration of IL- 6 with a simultaneous decrease in IL-10 concentration within 4-6 days can be considered prognostically significant in the development of a hyperactive systemic inflammatory response and sepsis.

This position is consistent with the literature in the notion of sepsis as a heterogeneous syndrome, characterized by a disbalance between immune hyperactivity and relative immune suppression. Moreover, it has been shown that the biomarkers used to evaluate the activity of these processes have sufficient potential for both recognizing sepsis and evaluating the effectiveness of its treatment, and for stratifying patients based on their basic biological response $[11,12]$.

Significant differences, both in concentration and dynamics of the soluble receptor for IL-2 in the compared groups, were also revealed. The highest level of this marker was observed throughout the term in patients of the $2^{\text {nd }}$ group. On the day 4-6, which are the determining factors for the further course of the disease, the concentration of IL-2R in the $1^{\text {st }}$ group was $1,594.19 \pm 966.88 \mathrm{U} / \mathrm{ml}$ (Med 1308 [931, 1,825.5]), 2,392.82 $\pm 2,110.97$ (Med 2,073 [1,294; $2,636.5]$ ) in the $2^{\text {nd }}$ group, and only $1,061.88 \pm 1,076.79$ (Med $736[463 ; 1,026]$ ) in the $3^{\text {rd }}$ group.

The biological role of the soluble receptor for IL-2 (IL-2R) is reduced to the need to intense anti-infective protection by enhancing the binding of IL-2 to IL-2 receptors. As a result, only lymphoid cells that are active against microorganisms are triggered. Soluble receptors bind excessive IL-2 in the bloodstream, thereby limiting the development of a systemic inflammatory response and inhibiting the progression of sepsis [13]. An increase in the concentration of IL-2R is found in the development of uncontrolled systemic inflammation, septic shock [14].

The results of our study demonstrate that the concentration of IL-2R in patients of group 1 and 2 up to 7-10 days of observation was characterized not only by statistically significant differences, but by more than three-fold decrease in group 1 and by minor variations in group 2 . In later periods, multidirectional changes were observed: a decrease to the level of the norm in the development of sepsis and a two-fold increase in it in case of a favorable course of the disease (see Fig. 1). Thus, an extremely unfavorable prognostic sign of the development of sepsis is a decrease in the concentration of IL-2R during within a week after the onset of the disease.

The change in the concentration of LPSBP in groups of patients with sepsis within 2 weeks was unidirectional and progressively decreased. On the contrary, in patients of the 3rd group, LBP increased 3-5 days later. Reducing the level of LBP in patients at high risk of developing sepsis should be considered as a prognostically unfavorable factor, as LBP in plasma serves as a "security system" that reacts to the micro-quantity of endotoxin and mobilizes mechanisms for neutralizing and eliminating the pathogen, and promotes inflammation, facilitating interaction of endotoxin with CD14 surface of monocytes. Simultaneously, the same protein together with free CD14 molecules ensures incorporation of endotoxin into lipoproteins, thereby neutralizing endotoxin and preventing hyperproduction of pro-inflammatory cytokines. Since LPSBP is of key importance in the early stages of the immune response, its level is usually elevated at the very beginning of the disease, which we also noted earlier [1]. Thus, a decrease in the plasma concentration of LBP in the clinical picture of the development of a purulent-septic complication indicates a lack of mechanisms that ensure neutralization of endotoxins, which is confirmed in a number of scientific publications [15].

Based on the results obtained by us and taking into account the scientific literature evidence that blood levels of LBP and other marker proteins are increasing both in non-infectious and infectious inflammatory responses, which complicate their use in seriously ill patients, it is advisable to carry out a comprehensive analysis that includes definition of IL-6 and LBP. This allows differentiating infectious and noninfectious inflammation, local or systemic infection, as well as predicting the severity of the course of sepsis and its outcomes [16].

The study of PCT should also be performed in dynamics during the first week after the onset of the disease or trauma, taking into account both our data and scientific literature indicating that high concentration of PCT starting with the first day after the onset of the disease or severe trauma and its secondary rise are precursors of the development of sepsis and/or multi-organ failure $[17,18]$.

The informative value of IL-10 is also significantly increased when it is simultaneously determined together with IL-6, since the significant differences in their concentration in the blood and the multidirectional dynamics of these interleukins suggest the development of sepsis and fatal outcome [2, 12].

The study of CRP showed that within the first 7-10 days the concentration of this protein in the blood of patients of the $1^{\text {st }}$ and $2^{\text {nd }}$ group with developed sepsis practically did not differ among themselves, but many times exceeded its level in patients of the $3^{\text {rd }}$ group. At a later date, there were no differences between the groups. Based on this, it can be concluded that CRP has the prognostic significance for the development of sepsis only in the early period of the disease. In the scientific literature, there are indications that concentration of CRP correlates not only with the development of sepsis, but also with its outcomes [19]. Probably, because of the small number of the $2^{\text {nd }}$ group of our 
study, and also because most of them died early, we were unable to reveal significant differences in the concentration of CRP in the deceased and those who survived.

\section{CONCLUSION}

The results obtained by us allowed to reveal significant differences in concentrations of the systemic inflammatory response markers and the dynamics of their changes in the period preceding the clinical manifestations of sepsis. It was found that it is possible to predict the development of sepsis and its unfavorable outcome with a large statistical probability in the study of paired samples of blood serum of patients received in the 1-3 and 4-6 days from the onset of the disease or severe trauma. In this respect, such results as the multidirectional changes in the concentrations in the blood of IL-6 and IL-10, LBR and more than three-fold increase in the level of IL-2R together with high concentrations of PCT and CRP are prognostically significant

FINDINGS

1. The highest concentrations in the blood of procalcitonin, C-reactive protein, IL-10 and IL-2R were revealed in the first 3 days in patients who died of sepsis.

2. High blood concentrations of IL- 6 and IL-10 in the first 3 days and different directions of their concentrations during the next 4-6 days indicate the development of sepsis with an unfavorable outcome.

3. More than three-fold decrease in IL-2R and two-fold IL-6 concentration and more than two-fold increase in IL-10 in comparison with baseline during the first week after the onset of the disease or injury are predictors of a fatal outcome.

\section{REFERENCES}

1. Gaini S., Koldkjaer O.G., Pedersen C., Pedersen S.S. Procalcitonin, lipopolysaccharide-binding protein, interleukin-6 and C-reactive protein in community-acquired infections and sepsis: a prospective study. Crit Care. 2006; 10(2): R53. PMID: 16569262. PMCID: PMC1550885. DOI: $10.1186 / \mathrm{cc} 4866$

2. Heper Y, Akalin E.H., Mistik R., et al. Evaluation of serum C-reactive protein, procalcitonin, tumor necrosis factor alpha, and interleukin-10 levels as diagnostic and prognostic parameters in patients with community-acquired sepsis, severe sepsis, and septic shock. Eur J Clin Microbiol Infect Dis. 2006; 25(8): 481-491. PMID: 16896829. DOI: 10.1007/s10096-006-0168-1.

3. Maier B., Lefering R., Lehnert M., et al. Early versus late onset of multiple organ failure is associated with differing patterns of plasma cytokine biomarker expression and outcome after severe trauma. Shock. 2007; 28(6): 668-674. PMID: 18092384.

4. Singer M., Deutschman C.S., Seymour Ch.W., et al. The Third International Consensus Definitions for Sepsis and Septic Shock (Sepsis-3). JAMA. 2016; 315(8): 801-810. PMID: 26903338. PMCID: PMC4968574. DOI:10.1001/jama.2016.0287

5. DeLong W.G. Jr., Born C.T. Cytokines in Patients with Polytrauma. Clin Orthop Relat Res. 2004; 422: 57-65. PMID: 15187834

6. Bulava G.V., Androsova M.V., Shabanov A.K., et al. Predictors of sepsis in patients with urgent conditions. Sklifosovsky Journal Emergency Medical Care. 2017; 6(1): 13-19. DOI:10.23934/2223-9022-2017-6-1-13-19 (In Russian).

7. Zweigner J., Gramm H.J., Singer O.C., et al. High concentrations of lipopolysaccharide-binding protein in serum of patients with severe sepsis or septic shock inhibit the lipopolysaccharide response in human monocytes. Blood. 2001; 98(13): 3800-3808. PMID: 11739189.

8. Remick D.G., Bolgos G.R., Siddiqui J., et al. Six at six: interleukin-6 measured $6 \mathrm{~h}$ after the initiation of sepsis predicts mortality over 3 days. Shock. 2002; 17: 463-467. PMID:12069181.

9. Kozlov V.K. Sepsis: etiology, immunopathogenesis, the concept of modern immunotherapy. Saint Petersburg: Dialekt Publ., 2006. 304 p. (In Russian).

10. Frink M., van Griensven M., Kobbe Ph., et al. IL-6 predicts organ dysfunction and mortality in patients with multiple injuries. Scand. $J$ Trauma Resusc Emerg Med. 2009; 17: 49. PMID: 19781105. PMCID: PMC2763001. DOI: 10.1186/1757-7241-17-49.

11. Miyaoka K., Iwase M., Suzuki R., et al. Clinical evaluation of circulating interleukin-6 and interleukin-10 levels after surgery-induced inflammation. J Surg Res. 2005; 125 (2): 144-150. PMID: 15854666. DOI: 10.1016/j.jss.2004.12.001.

12. Manley M.O., O’Riordan M.A., Levine A.D., Latifi S.Q. Interleukin 10 extends the effectiveness of standard therapy during late sepsis with serum interleukin 6 levels predicting outcome. Shock. 2005; 23(6): 521-526. PMID: 15897804.

13. Rubin L.A., Nelson D.L. The soluble interleukin-2 receptor: Biology, function, and clinical application. Ann Intern Med. 1990; 113: 619-627. PMID: 2205142 .

14. Ostanin O.A., Leplina O.Yu., Shevela E.Ya., at al. The assessment of cytokine pattern in patients with severe sepsis using the Bio/Plex/protein assay system. Tsitokiny i vospalenie. 2004; 3(1): 20-27. (In Russian).

15. Anisimova N.Yu., Gromova E.G., Kuznetsova L.S., Kiselevskiy M.V. Prognosticheskoe znachenie syvorotochnogo urovnya lipopolisakharida i lipopolisakharid-svyazyvayushchego belka u onkologicheskikh bol'nykh s sepsisom. Zhurnal mikrobiologii, epidemiologii i immunobiologii. 2011; (2): 82-84. (In Russian)

16. Prucha M., Herold I., Zazula R., et al. Significance of lipopolysaccharide-binding protein (an acute phase protein) in monitoring critically ill patients. Crit Care Med. 2003; 7(6): R154-159. PMID: 14624690. PMCID: PMC374378. DOI: 10.1186/cc2386.

17. Sakran J.V., Michetti C.P., Sheridan M.J., et al. The utility of procalcitonin in critically ill trauma patients. J Trauma Acute Care Surg. 2012; 73(2): 413-418. PMID: 22846948. DOI: 10.1097/TA.0b013e31825ff5b7.

18. Reinhart K., Meisner M. Biomarkers in the critically ill patient: procalcitonin. Crit Care Clin. 2011; 27(2): 253-263. PMID: 21440200. DOI: 10.1016/j.ccc.2011.01.002

19. Lobo S.M., Lobo F.R., Bota D.P., et al. C-reactive protein levels correlate with mortality and organ failure in critically ill patients. Chest. 2003; 123(6): 2043-2049. PMID: 12796187. 